\title{
Curriculum Reform Study of Policing Technique and Tactics under Rule of law
}

\author{
Jinquan Zhao
}

\author{
Hainan Vocational College of Political Science and Law, Haikou Hainan, 571100, China
}

Keywords: Rule by law, Policing technique and tactics curriculum, Reform, Study.

\begin{abstract}
At the present stage, during the development and practice process, policing technique and tactics curriculum in our public security colleges gradually appear their own existing problems, which directly influence the training quality and result in difficulties to get ideal law enforcement effects. Since the policing technique and tactics curriculum belong to the key contents of teaching and training in public security colleges, the curriculum reform is imperative under Rule of law.
\end{abstract}

\section{Introduction}

During teaching and training in public security colleges, the function of policing technique and tactics curriculum is of great significance, and meanwhile the key of curriculum teaching reform. Party committee of Ministry of Public Security in our country has clearly pointed out that it needs to build wholesome educational training institutional system and basic system, innovate content and form of educational training, further study and build work system identical to public security practice and public security characteristics and finally obviously enhance police officers' comprehensive quality and actual combat skills. After proposal and implementation of the above work system, public security colleges must build and implement training pattern of integrated "teaching, learning, training and fighting" and meanwhile enhance requirement of teaching and training quality of policing technique and tactics curriculum.

\section{Prominent Problem Study in Teaching and Training of Policing Technique and Tactics under Rule of law}

\section{Serious disjunction of training content and actual combat}

In recent years, with the further development of "troop training", many people's policemen study and learn tactical training in public security colleges in each regions. And the tactical training hoes through the process from high interests to boredom. The main reason is that scene and scale of tactical training are relatively large and very boisterous, which have big difference from actual combat. At the same time, in practical training, it is hard to feel the feeling of tension. Thus, after long term training process, feeling of freshness would be gone and they would feel boring finally.

\section{Many training problems in weapon usage}

To policemen, weapon usage is a must policing skill for them. If the weapon is used rationally and correctly, it could not only frighten criminal offenders but also effectively prevent the occurrence of criminal activities to protect the masses and their property. Once the weapon is used incorrectly, the final result would be very serious, which shows the importance of training of weapon usage. However, such training doesn't possess general training content and standard throughout the country. Thus, when public security colleges carry out weapon usage training in most areas, they make the contents and standard themselves which finally result in different levels of weapon usage. In addition, public 
security colleges in different areas always despise laws and regulations of weapon usage but pay attention to shoot skill training. And students haven't trained to correctly use weapons, don't know when and how to use guns. Thus, after the weapon usage training, many policemen can still not apply their knowledge in practical law enforcement and the weapons are of no use for them.

\section{Single and dull curriculum content in attack and defense as well as command}

At present, during the control training in public security colleges, the specific training content is very single and most of them take individual active training as the emphasis, with control skill as assistant role. In addition, such control skills and methods close to actual combat as "two controlling one" and "three controlling one" are still ignored and not brought into the main training contents ${ }^{[1]}$. On this basis, the effects of control training of team law enforcement are not ideal, even the training to handcuffs, spontoon or pepper propellant being not standard. The training strength is not enough, and even public security colleges don't have the above training courses.

\section{Weak law enforcement safety philosophy}

During the law enforcement of policemen, if it is to ensure safety, the most important premise is to have safety philosophy. However, at this stage, during the teaching and training of policing technique and tactics curriculum in our public security colleges, the problem of valuing tactics and despising idea is very serious. Thus, there is no intensification to law enforcement safety philosophy during training process.

\section{Way of Curriculum Reform Policing Technique and Tactics under Rule of Law}

By analyzing the existing problems of teaching and training of policing technique and tactics curriculum under Rule of Law, it has great influence to the training quality of policing technique and tactics and negative effects in practical law enforcement. Therefore, it should reform and innovate corresponding curriculum, fully advance instructors team construction. Only in this way could better perfect policing technique and tactics curriculum in public security colleges and promote training quality.

\section{Training curriculum reform of weapon usage}

Since the training of weapon usage could guarantee safety, learning relevant laws and regulations could help to use weapons according to law and the normative motor skills are the key point of training. Thus, during the reform of course teaching of weapon usage training, the most important and basic is to unify content of courses, guarantee collective preparation of instruction before class and ensure training content close to actual combat.

Training content, laws and regulations as well as training forms close to practical law enforcement

Purpose to carry out weapon usage training is not only the skill training but also the actual combat training with both skills and laws and regulations. Therefore, it must guarantee students to expertly master and learn specific condition during training process, being when to use the weapons. In this way, students could indeed feel application by learning and initiatively and consciously put into curriculum training. By this training way, it could help policemen to enhance and promote operability of weapon usage during practical law enforcement ${ }^{[2]}$. Therefore, it mush organize experts with relevant laws and regulations to participate in instructor team of weapon usage training at short notice.

Curriculum instructor and students should enhance safety awareness

All instructors and colleges should expertly master weapon safety regulations and meanwhile always run through the whole process of weapon usage training. Thus, it should strictly assess gun safety regulations theory and practice of instructors and students to guarantee safe and reliable weapon usage training, fully cultivate students' weapon usage skills and let government, the public and students themselves at ease. 
During the process of carrying out weapon usage training, all instructors must regularly collective preparation of instruction and realize unification and consensus in such aspects as ideology, instructor command and motor skills. If the content and plan of teaching and training are appointed, it must guarantee instructors always strictly carry out that. At the same time, the making, amendment and even changing of content and plan of teaching and training should be reported to the offices of teaching affairs in the colleges for file.

Teaching and training content unified and close to actual combat

At the present stage, during the teaching process of weapon usage in our public security colleges, since the number of using bullets of students is not much, organization and training for instructors would be difficult in practical training process. Most of the time would usually be used for empty guns training. If things go on like this, it would gradually form the teaching pattern that students are trained mainly with empty guns while firing practice becomes the assistant teaching method ${ }^{[3]}$. However, firearms training is a kind of skill. Thus, it must train with firing practice that could guarantee students feeling deeply and effectively promoting their shooting skills. Because the number of using bullets is not much, the set of teaching contents is not rational which increase difficulty of teaching and training. Even if students are willing to master this skill, they would be affected by objective condition and hard to exercise, finally feeling boring to training. Thus, it must effectively increase the number of using bullets of students and unify its standard in national public security colleges. At the same time, it needs to divide weapon usage training into two parts such as basic shooting and practical shooting, paying more attention to conclusive shooting training.

\section{Curriculum reform of control, offense and defense}

Firstly, it needs to actively carry out investigation and survey, including basic level interview, policemen discussion or practical management and analysis to typical cases to further form perfect and feasible control theory system at short notice.

Secondly, when carrying out offense and defense as well as control teaching, it should choose practical contents easy to learn and adopt the main training direction of "many controlling one" ${ }^{[4]}$. Since the single policeman's equipment are distributed comprehensively, it needs to add trainings in spontoons or pepper propellant in teaching.

Thirdly, with teaching and training of "many controlling one" as the key point, it should fully show team work and continuously enhance training effects. Since the main purpose of policemen is to control others rather than hurt or shoot them, it should take control technology as key point to the choice of teaching contents, continuously enhance team control, assist with basic skill of boxing and guarantee choosing control actions being easy, practical and understandable.

Fourthly, it should intensify basic formation training of antiriot and change its application of usually in policing technique and tactics performance.

\section{Curriculum reform of tactical training}

Firstly, during the tactics teaching and training curriculum, it should adopt team teaching method. All instructors need collective preparation of instruction and clear the individual responsibility in teaching and training.

Secondly, it should intensify policing tactics idea and theory teaching. When instructing policing actions, theory and safety philosophy teaching is the most important basis. Thus during the process of teaching theory and safety philosophy, it could teach by multimedia courseware and choose fresh cases. While applying the multimedia technology, it could overall and multi-angle show the teaching contents to better highlight teaching link. In addition, case teaching could make students deeply understanding the significance of life and safety during the process of practical law enforcement. With typical cases, it could realize the purpose of linking theory of teaching contents with practice, enrich teaching contents, fully cultivate students' analyzing problems' ability and enhance their ability of solving problems. 
At last, it should fully carry out maneuver teaching of actual combat. Based on synthesis simulated training safety, it could adopt teaching pattern of colorful bullets training. Under the background of comprehensive maneuver, it could make policing tactics idea and theory always running through the process, organically integrate theory teaching and practical application with grouping actual combat training, which could make students to better learn and expand their knowledge and skills. With suspicion cars inspection cases as example, during the actual combat maneuver, it should firstly stop the suspicion car, approach to it, control it by command and prepare to shoot. The specific inspection contents include certificate inspection, application of control tactics to criminal suspect, etc. Such teaching of actual combat maneuver could continually improve students' abilities.

\section{Overall construction of Instructor Team}

Firstly, it should guarantee all instructors have correct understanding to the policing actual combat training. During the training process, there is no expert but unified, unit and harmonious instructor team, which is also the important premise to the successful training of policing actual combat. At the same time, it also needs all instructors to try their best to integrate with team spirit.

Secondly, it should enhance instructors' professional idea and team spirit, fully infuse them with sincere and making the best of professional idea to run through the process of teaching and training.

Thirdly, it should actively encourage instructors to innovate and reform, to guarantee instructors learning exchange, go deep into basic level, invite experienced instructor to carry out speeches, make all instructors adapting to era development, actively update and change idea, change the teaching method and mode and arise instructors' enthusiasm ${ }^{[5]}$. At the same time, it should intensify the application of case teaching method to deeper study and innovate policing skills and tactics teaching method and explore new training method and teaching method. In addition, according to the new situation and tasks of public security work, instructors need to improve policing skills and tactics teaching method, guarantee public security practice close to the actual combat, continually enhance teaching quality and actively promote the sustainable development of public security colleges.

Fourthly, it should go deep into digging instructors' potency and promote professional quality of policing actual combat training. All instructors should undertake course teaching of teaching and research office, conscientiously try hard to study and actively apply for undertaking multiple policing practical training course teaching. In this way, instructors could realize the goals of good at many things and expert in one or good at many things and expert in two. In addition, policing training department in public security colleges needs to set accrediting and validating agency for instructor curriculum holding to examine the instructors undertaking not only this curriculum but also other teaching tasks, further guaranteeing possessing the teaching qualification, actively promoting their study and enhancing their comprehensive quality.

\section{Conclusion}

To sum up, under the background of Rule of Law, there are still some existing problems in the course teaching of policing technique and tactics in our public security colleges. Thus in order to guarantee the good development of this course teaching, it must do reformation to guarantee closing to the policing actual combat demand, realizing unification of training idea and skill tactics and always running through the process of policing actual combat.

\section{References}

[1] Zhao Jinquan. Curriculum Reform Study of Policing Technique and Tactics under the Background of Legal Society, Curricular Educational Research (New Teacher Education), 2012(9):11,13.

[2] Zhang Libing, Curriculum Reform Analysis of Policing Technique and Tactics in public security colleges, journal of Guizhou Police Officer Vocational College, 2011,23(5):122-124,128. 
[3] Shao An, Evolution Analysis of Development and Research Method of Policing Technique and Tactics in China, journal of Yunnan Police Officer Academy,2013(6):70-74,83.

[4] Wang Qaing, Lu Zhaoming, Li Ming, etc. Exploration and Study of Actual Combat Training of Policing Technique and Tactics, journal of Chinese People's Public Security University (JCR Science Edition) ,2015,21(3):107-109.

[5] Zhao Hui, Modularization Curriculum System Construction of Policing Technique and Tactics Based on Vocational Ability, journal of Taiyuan Urban Vocational College, 2014(1):119-120. 